\title{
Rhizoxin Analogs Contribute to the Biocontrol Activity of a Newly Isolated Pseudomonas Strain
}

\author{
Kasumi Takeuchi, ${ }^{1}$ Naomi Noda, ${ }^{1}$ Yuichi Katayose, ${ }^{2}$ Yoshiyuki Mukai, ${ }^{2}$ Hisataka Numa, ${ }^{2}$ \\ Kosumi Yamada, ${ }^{3}$ and Nobutaka Someya ${ }^{4}$ \\ ${ }^{1}$ Division of Plant Sciences and ${ }^{2}$ Agrogenomics Research Center, National Institute of Agrobiological Sciences, 2-1-2 \\ Kannondai, Tsukuba, Ibaraki 305-8602, Japan; ${ }^{3}$ Faculty of Life and Environmental Sciences, University of Tsukuba, \\ Ibaraki 305-8572, Japan; and ${ }^{4}$ Hokkaido Agricultural Research Center, National Agriculture and Food Research \\ Organization, 9-4 Shinsei-minami, Memuro-cho, Kasai-gun, Hokkaido 082-0081, Japan
}

Submitted 29 September 2014. Accepted 4 December 2014.

Two strains of Pseudomonas sp., Os17 and St29, were newly isolated from the rhizosphere of rice and potato, respectively, by screening for 2,4-diacetylphloroglucinol producers. These strains were found to be the same species and were the closest to but different from Pseudomonas protegens among the sequenced pseudomonads, based on $16 \mathrm{~S}$ ribosomal RNA gene and whole-genome analyses. Strain Os17 was as effective a biocontrol agent as reported for $\boldsymbol{P}$. protegens Cab57, whereas strain St29 was less effective. The whole-genome sequences of these strains were obtained: the genomes are organized into a single circular chromosome with $6,885,464 \mathrm{bp}, 63.5 \% \mathrm{G}+\mathrm{C}$ content, and 6,195 coding sequences for strain Os17; and with $6,833,117 \mathrm{bp}$, $63.3 \% \mathrm{G}+\mathrm{C}$ content, and 6,217 coding sequences for strain St29. Comparative genome analysis of these strains revealed that the complete rhizoxin analog biosynthesis gene cluster (approximately $79 \mathrm{~kb}$ ) found in the Os17 genome was absent from the St29 genome. In an $r z x B$ mutant, which lacks the polyketide synthase essential for the production of rhizoxin analogs, the growth inhibition activity against fungal and oomycete pathogens and the plant protection efficacy were attenuated compared with those of wild-type Os17. These findings suggest that rhizoxin analogs are important biocontrol factors of this strain.

Pseudomonas protegens and some other root-colonizing pseudomonads classified into the $P$. fluorescens group are effective biocontrol strains, which suppress plant diseases in the rhizosphere. $P$. protegens strains Pf-5 and CHA0 (previously called $P$. fluorescens Pf-5 and CHA0, respectively) have been used as model strains in studies on the biosynthesis of several extracellular enzymes, such as AprA protease, and sec-

The complete genome sequences of Pseudomonas sp. strains Os17 and St29 have been deposited in the DDBJ/EMBL/GenBank database under accession numbers AP014627 and AP014628, respectively.

Current address for Nobutaka Someya: Headquarters, National Agriculture and Food Research Organization, 3-1-1 Kannondai, Tsukuba, Ibaraki 3058517, Japan.

Corresponding author: K. Takeuchi; Telephone: +81 29838 7005, Fax: +8129838 7408, E-mail: kasumit@affrc.go.jp

* The $\boldsymbol{e}$-Xtra logo stands for "electronic extra" and indicates that six supplementary figures and six supplementary tables are published online.

(C) 2015 The American Phytopathological Society ondary metabolites with antibiotic activity, such as 2,4-diacetylphloroglucinol (DAPG), pyrrolnitrin (PRN), and pyoluteorin (PLT) (Haas and Keel 2003). The complete genome data of strains Pf-5 and CHA0 and other pseudomonads are available at the Pseudomonas.com website (Winsor et al. 2011) and provide detailed annotation data of these strains.

The expression of biocontrol factors depends on the Gac/Rsm signal transduction pathway (Lapouge et al. 2008). The Gac/Rsm cascade is initiated by the GacS/GacA two-component system. The GacS sensor kinase is known to be phosphorylated and activates the cognate GacA response regulator by phosphotransfer during slow growth and in the presence of unidentified signal molecules. In $P$. protegens $\mathrm{CHA} 0$, activated GacA promotes the transcription of noncoding small RNAs (sRNAs) termed RsmX, RsmY, and RsmZ. These sRNAs have high affinity for the RNA-binding protein RsmA and also for the RsmA paralog RsmE in strain CHA0 (Heeb et al. 2002; Kay et al. 2005; Reimmann et al. 2005; Valverde et al. 2003). The RsmA and RsmE proteins repress the translation of genes involved in secondary metabolism during trophophase. When RsmX, -Y, and -Z sRNAs are induced in idiophase, they relieve the translational repression of target genes by sequestering the RsmA and RsmE proteins, thereby allowing the synthesis of secondary metabolites (Haas and Défago 2005; Kay et al. 2005, 2006). Thus, mutants defective in the Gac/Rsm signal transduction pathway have a reduced ability to produce such biocontrol factors and to suppress plant diseases (Haas and Défago 2005; Kim et al. 2011). Two additional sensors, termed RetS and LadS, were shown to provide input into the Gac/Rsm pathway in $P$. fluorescens and $P$. aeruginosa (Goodman et al. 2009; Humair et al. 2009). RetS inhibits and LadS activates the activity of the Gac/Rsm pathway and, in this way, both sensors affect the expression of target genes and biocontrol factors (Humair et al. 2009). Krebs cycle intermediates and alarmone ppGpp (guanosine tetraphosphate) are also involved in this pathway via the expression of Rsm sRNAs (Takeuchi et al. 2009, 2012).

In terms of the effective and ecological application of biocontrol agents, screening for pseudomonads that benefit plants has led to advances in biocontrol research. Moreover, the complete genomic sequence of strain Pf-5 (Paulsen et al. 2005) has provided new insights into the molecular basis underlying the pseudomonad-mediated suppression of plant disease. For example, novel natural products, including the cyclic lipopeptide orfamide A (Gross et al. 2007), rhizoxin analogs (Loper et al. 2008), and the insect toxin FitD (Péchy-Tarr et al. 2008), have been discovered through genomics-guided approaches in strains 
Pf-5 and CHA0. Comparative genome analysis among strains in the P. fluorescens group has also contributed to the understanding of other strains (Loper et al. 2012). In our previous work, we isolated and fully sequenced biocontrol strain $P$. protegens Cab57, and compared its genome with those of Pf-5 and CHA0. Even within the same species ( $P$. protegens), comparative genome analysis revealed that each strain builds up strain-specific genomic repertoires for the biosynthesis of secondary metabolites and niche adaptation (Takeuchi et al. 2014).

In the present study, we aimed to screen biocontrol pseudomonad strains close to but different from $P$. protegens Cab57, with the expectation that their comparative genome analyses would contribute to the identification of factors involved in the biocontrol efficacy of newly isolated strains. We showed that two of the isolates producing DAPG exhibited different biocontrol potential against Pythium damping-off and root rot in the cucumber. We named the effective biocontrol isolate Os17 and the other one St29, and conducted whole-genome sequencing on them. A whole-genome comparison of these related strains revealed that they are the same species and they have several strain-specific genomic regions. Among these regions, the complete rhizoxin analog biosynthesis gene cluster (approximately $79 \mathrm{~kb}$ ) specific to the Os17 genome was characterized in detail for its role in biocontrol activity of this strain.

\section{RESULTS AND DISCUSSION}

\section{Isolation of DAPG-producing pseudomonads closely related to but different from reported strains of $P$. protegens.}

Approximately 2,800 fluorescent pseudomonads were obtained from plant roots. On the basis of polymerase chain reaction (PCR) analysis of this collection to identify the phlD ${ }^{+}$ strain, 48 isolates were selected as candidates of DAPG-producing isolates and their production activities were confirmed by thin-layer chromatography (TLC) (data not shown). Of the 48 strains, five were PCR positive for all of the three other antibiotic biosynthetic genes (for PRN, PLT, and hydrogen cyanide $[\mathrm{HCN}])$ that are typically found in $P$. protegens (Takeuchi et al. 2014). Actually, one of these five strains, Cab57, was identified as $P$. protegens based on $16 \mathrm{~S}$ ribosomal RNA (rRNA) gene analysis (with $100 \%$ identity) and wholegenome analysis (Takeuchi et al. 2014). Among the remaining strains, 39 strains were PCR positive for the hcn gene but negative for PRN and plt genes. On the basis of analysis of $16 \mathrm{~S}$ rRNA sequence variations, seven of these strains were found to have $99 \%$ similarities in their 16S rRNA gene with that of $P$. protegens, which was the highest homology among the sequenced strains. Among the seven strains, 16S rRNA sequences of five strains, all of which are from the rhizosphere of rice (Oryza sativa L.) growing in a paddy field in Ibaraki, showed $100 \%$ identity.

We selected one of these five strains. named Os17, for further analysis. We also selected one of the remaining two strains, named $\mathrm{St} 29$, which was isolated from the rhizosphere of potato (Solanum tuberosum L.) growing in a field in Ibaraki. Strains Os17 and St29 shared 99.94\% identity in their 16S rRNA, suggesting that these two strains belong to the same species. For the detection of antibiotic activity, strains were grown on a nutrient broth supplemented with $1 \%$ glucose (NBglu), which is conducive to DAPG production in $P$. fluorescens Pf-5 (Kidarsa et al. 2011). The growth inhibition activities of strains Os17 and St29 against Bacillus subtilis on an NBglu agar plate were assessed by the halo size, giving values of $13.5 \pm 0$ and $13.3 \pm 0.2 \mathrm{~mm}$, respectively. DAPG production levels by these strains were determined by high-performance liquid chromatography (HPLC). The concentrations of DAPG were $498 \pm 95 \mathrm{nmol}$ and $207 \pm 13 \mathrm{nmol}$, respectively, per optical density at $600 \mathrm{~nm}\left(\mathrm{OD}_{600}\right)$ in the strains grown in liquid NBglu to $\mathrm{OD}_{600}=4.0$ (one $\mathrm{OD}_{600}$ unit corresponds to approximately $1 \times 10^{9}$ cells $\left./ \mathrm{ml}\right)$.

\section{Biocontrol efficacy of strains Os17 and St29.}

To investigate the biocontrol activity of strains Os17 and St29 in a natural habitat, we adopted a cucumber-Pythium ultimum pathosystem, which enabled us to evaluate plant protection efficacy by measuring the root and shoot weights. Strain Os17 was as effective a biocontrol agent as reported for strain Cab57, whereas strain St29 was less effective than strain Os 17 , with $95 \%$ confidence (Table 1).

\section{The genome structures of Os17 and St29.}

Although DAPG is one of the most important antimicrobial compounds produced by biocontrol strains of the Pseudomonas fluorescens group, there are many other antibiotic metabolites, some of which have been demonstrated to be involved in their biocontrol activity. Furthermore, other bacterial traits such as siderophore production and motility are also important

Table 1. Suppression of Pythium damping-off and root rot in the cucumber by Pseudomonas protegens Cab57, Pseudomonas sp. Os17, and Pseudomonas sp. St29

\begin{tabular}{|c|c|c|c|c|c|}
\hline \multirow[b]{2}{*}{ Bacterial strain added $^{\mathrm{z}}$} & \multirow[b]{2}{*}{ Pythium added $^{\mathrm{z}}$} & \multicolumn{2}{|c|}{ Per flask $^{\mathrm{x}}$} & \multicolumn{2}{|c|}{ Root fresh weight per flask $(g)^{y}$} \\
\hline & & Surviving plants (\%) & Shoot fresh weight (g) & 1st Exp. & 2nd Exp. \\
\hline None & - & $100 \mathrm{a}$ & $0.71 \mathrm{a}$ & $0.36 \mathrm{a}$ & $0.30 \mathrm{a}$ \\
\hline Cab57 & _- & $100 \mathrm{a}$ & $0.73 \mathrm{a}$ & $0.37 \mathrm{a}$ & $0.29 \mathrm{a}$ \\
\hline Os17 & - & $100 \mathrm{a}$ & $0.68 \mathrm{a}$ & $0.38 \mathrm{a}$ & $0.31 \mathrm{a}$ \\
\hline St29 & - & $100 \mathrm{a}$ & $0.72 \mathrm{a}$ & $0.42 \mathrm{a}$ & $0.31 \mathrm{a}$ \\
\hline None & + & $6 c$ & $0.21 \mathrm{~d}$ & $0.11 \mathrm{~d}$ & $0.10 \mathrm{~d}$ \\
\hline Cab57 & + & $75 \mathrm{a}$ & $0.45 \mathrm{bc}$ & $0.21 \mathrm{c}$ & $0.19 b c$ \\
\hline Os17 & + & $83 \mathrm{a}$ & $0.47 \mathrm{~b}$ & $0.27 \mathrm{~b}$ & $0.21 \mathrm{~b}$ \\
\hline St29 & + & $50 \mathrm{~b}$ & $0.39 \mathrm{c}$ & $0.17 \mathrm{~cd}$ & $0.15 \mathrm{~cd}$ \\
\hline
\end{tabular}

${ }^{\mathrm{x}}$ Data represent the averages of 10 replicates (flasks containing three cucumber plants) per treatment without Pythium ultimum and 16 replicates per treatment with $P$. ultimum. Means within the same column followed by different letters $(\mathrm{a}-\mathrm{d})$ are significantly different $(P<0.05)$ according to Tukey's honestly significant difference (HSD) test.

${ }^{\text {y }}$ Data represent the averages of five replicates (flasks containing three cucumber plants) per treatment without $P$. ultimum and eight replicates per treatment with $P$. ultimum in each experiment. Means within the same column followed by different letters $(\mathrm{a}-\mathrm{d})$ are significantly different $(P<0.05)$ according to Tukey's HSD test.

${ }^{\mathrm{z}}$ Pseudomonas strains were added at $10^{7} \mathrm{CFU} / \mathrm{g}$ of vermiculite contained within $100-\mathrm{ml}$ flasks ( $30 \mathrm{~g}$ of soil per flask), after planting three 92 -h-old, sterilegrown cucumber seedlings per flask. P. ultimum was added as a millet-seed inoculum at $2.5 \mathrm{~g} / \mathrm{kg}$ of vermiculite before planting. Plants were harvested after 7 days. 
for efficient plant protection (Haas and Keel 2003). Therefore, the higher efficiency of DAPG production in strain Os17 may not solely account for the advantage in biocontrol activity. To obtain overviews of functionality and features of the newly isolated biocontrol strain Os17, we conducted whole-genome sequencing. We also obtained the whole-genome data of strain St29, enabling comparison between two strains. The genomes are organized into a single circular chromosome with $6,885,464$ bp and $63.5 \% \mathrm{G}+\mathrm{C}$ content for strain Os17, and with $6,833,117 \mathrm{bp}$ and $63.3 \% \mathrm{G}+\mathrm{C}$ content for strain St29, and the genomes are predicted to encode 6,195 and 6,217 proteins, respectively. The general genomic features of strains Os 17 and St29 as well as those of $P$. protegens Cab57 are listed in Table 2. Strains Os17 and St29 were deposited in the MAFF Genebank, National Institute of Agrobiological Sciences, as MAFF212089 and MAFF212090, respectively.

To define species, the JSpecies program has been commonly used to compare two genomes (Richter and Rosselló-Móra 2009); thus, we applied this program for the species identification of strain Os17 and strain St29. The average nucleotide identity, calculated with BLAST algorithm (ANIb) values, which provides a numerical and stable species boundary (Richter and Rosselló-Móra 2009), confirmed the categorization of strains Os17 and St29 into the same species $(98.81 \%)$ (Table 3); values higher than $96 \%$ were found for strains of the same species. On the other hand, the values were lower than $90 \%$ when compared with the genome of strain Os17 and those of $P$. protegens strains (Cab57, CHA0, and Pf-5). Together with ANIb, tetranucleotide frequency correlation coefficients (TETRA) reinforced the objective boundary for species circumscription when TETRA values $>0.99$; however, both values should agree (Richter and Rosselló-Móra 2009). Comparison of the genomes of strains Os17 and St29 showed a value of $>0.999$ (Table 3 ). We also performed comparisons with genomes of other $P$. fluorescens group strains: $P$. chlororaphis subsp. aureofaciens 30-84, P. fluorescens Pf0-1, $P$. fluorescens SBW25, and $P$. fluorescens A506, covering all three of the subclades of the $P$. fluorescens group, in which the strains are divided as follows: group $1=P$. protegens $\mathrm{Pf}$ 5, P. chlororaphis subsp. aureofaciens strains 30-84, and O6; group $2=P$. fluorescens strains Pf0-1 and Q2-87 and P. brassicacearum Q8r1-96; and group $3=P$. fluorescens strains SS101, A506, and SBW25 and P. synxantha BG33R (Loper et al. 2012). ANIb values were lower than those of $P$. protegens strains, suggesting that strains Os17 and St29 are the closest relatives to $P$. protegens among the studied strains, although they are not identified as $P$. protegens.

Then, we constructed a whole-genome-based phylogenetic tree to illustrate the taxonomic position of strains Os17 and St29 among other $P$. fluorescens group strains by using a reference sequence alignment-based phylogeny builder (REAL-
PHY) (Bertels et al. 2014). These two strains fall into the same subtree, creating a new branch within group 1 (Supplementary Fig. S1), and these are the closest relatives to strains of $P$. protegens, supporting the results of the species definition mentioned above. On the basis of this method, $P$. fluorescens group strains were separated into three subclades, consistent with the report by Loper and associates (2012), in which the tree was based on concatenated alignments of 10 core housekeeping genes.

\section{Core and pan-genome analysis.}

A BLASTp search of strains OS17, St29, and Cab57 revealed that unique coding sequences (CDS) were most abundant in strain Cab57 (Fig. 1), reflecting its heterology among the three strains. The number of Cab57-specific CDS was 736, whereas it was 234 when comparing the genome with those of the strains of P. protegens Pf-5 and CHA0 (Takeuchi et al. 2014). Strains Os17 and St29 shared 519 CDS, except for core genes $(5,321)$, some of which may reflect the species-specific repertoire, as mentioned below. Strain Cab57 shared more CDS with strain Os17 than with strain St29 (Fig. 1) and, of the 99 CDS shared specifically by Cab57 and Os17, 55 were phagerelated genes, as also mentioned below.

Concerning biocontrol factors, two gene clusters ( $h \mathrm{cn}$ and $p h l$ ) encoding antibiotic metabolites were conserved in the genomic sequence of strains Os17 (gene ID 2580-2582 and 5893-5900) and St29 (gene ID 2684-2686 and 5899-5906), whereas two other gene clusters (plt and prn) were absent, which supported the PCR analysis results mentioned above. The aprA gene cluster, for the major extracellular protease AprA, is conserved in the two strains (gene ID 2865-2870 for Os17 and gene ID 2982-2988 for St29), although a homolog of the aprE gene presents as a hybrid of two adjacent genes (2986 and 2987) in St29 (Supplementary Table S1).

The reported genes associated with the Gac/Rsm signal transduction pathway were fully conserved in the Os17 genome, with $>90 \%$ homology to those of Pf-5 (Supplementary Table S2). All of these homologs of Os17 were completely conserved in the St29 genome, with $100 \%$ homology (data not shown), suggesting that the components of the Gac/Rsm cascade are the core of each group of pseudomonads as an antibiotic producer.

Other typical gene clusters encoding biocontrol factors were also explored (Supplementary Table S3). Gene clusters for pyoverdine $(p v d)$, whose product has been commonly reported in $P$. protegens, were conserved in the Os17 genome in four different loci (gene ID 3176-3177, 4178-4197, 4256-4266, and 4277-4279) as reported in Pf-5 (Gross and Loper 2009) and Cab57 (Takeuchi et al. 2014), although genes of 4191 to 4195 showed lower homologies (40 to 53\% identity) to these strains. The gene cluster for enantio-pyochelin $(p c h)$, which has been

Table 2. General genomic features of Pseudomonas protegens Cab57, Pseudomonas sp. Os17, and Pseudomonas sp. St29

\begin{tabular}{|c|c|c|c|c|c|c|}
\hline Strains & Genome size (bp) & CDS number & G+C content $(\%)$ & rRNA genes number & tRNA genes number & Accession number \\
\hline Cab57 & $6,827,892$ & 6,186 & 63.3 & 16 & 68 & AP014522 \\
\hline Os17 & $6,885,464$ & 6,195 & 63.5 & 19 & 70 & AP014627 \\
\hline St29 & $6,833,117$ & 6,217 & 63.3 & 19 & 68 & AP014628 \\
\hline
\end{tabular}

Table 3. Whole-genome comparison of strain Os17 with those of St29 and other Pseudomonas fluorescens group

\begin{tabular}{|c|c|c|c|c|c|c|c|}
\hline \multirow[b]{2}{*}{ Comparison $^{\mathrm{z}}$} & \multicolumn{7}{|c|}{ Strains within the $P$. fluorescens group } \\
\hline & St29 & Cab57 & CHAO & Pf-5 & Pf0-1 & SBW25 & A506 \\
\hline $\operatorname{ANIb}(\%)$ & 98.81 & 89.72 & 89.63 & 89.45 & 81.34 & 80.67 & 80.41 \\
\hline TETRA value & 0.99987 & 0.9953 & 0.99518 & 0.99524 & 0.96023 & 0.94454 & 0.94047 \\
\hline
\end{tabular}

${ }^{\mathrm{z}} \mathrm{ANIb}=$ average nucleotide identity, calculated with BLAST algorithm, and TETRA = tetranucleotide frequency correlation coefficients to Os 17. 
isolated from strain $\mathrm{CHAO}$ and its gene cluster and is fully conserved in Pf-5 (Youard et al. 2007), was also conserved in strain Os17. Both $p v d$ and pch clusters were conserved in strain St29.

The gene cluster for orfamides, which has been identified in strain Pf-5 from mining of Pseudomonas genomes (Gross et al. 2007) and also found in the genomes of CHA0 and Cab57 (Takeuchi et al. 2014), was not conserved in the two genomes of Os17 and St29. Phenazine is an antibiotic produced by some Pseudomonas strains (excluding $P$. protegens). The homology search of the gene cluster over the entire genome suggested that the known pathways for the synthesis of phenazine may not be present in both Os17 and St29 strains.

Among the 519 CDS specifically shared by the genomes of Os17 and St29 (Fig. 1), we listed regions including at least four continuous open reading frames (ORFs) in order to obtain an overview of species-specific traits (Supplementary Table S4, clusters OS1 to OS33). Some of these clusters should be mentioned, as follows: OS1 for O-antigen, OS7 for type VI secretion, OS25 for fimbriae, OS26 for secretion, and OS29 for pilus. These homologs were also absent from other strains of $P$. protegens $\mathrm{Pf}-5$ and $\mathrm{CHA} 0$ at $>60 \%$ identify, suggesting that they may contribute to build up the uniqueness of Os17 and St29 and fall into the same species. OS3, OS16, and OS21 were identified as parts of secondary metabolite clusters using the antiSMASH program (Blin et al. 2013). According to this program, OS3 was predicted to encode bacteriocin. OS16 (located at 3369090..3376837 in the Os17 genome) was part of a large hit region (3266543.. 3385308), including $r z x$ cluster (3285485..3365308), although the relevance of this is not clear. OS21 (located at 4152719 .. 4168145 in the Os17 genome) was also part of a large hit region (4111697..4163109), including mitomycin clusters O6 (4111262..4130682) and O7 (4131697..4152441).

\section{Cab57}

$(6,186)$

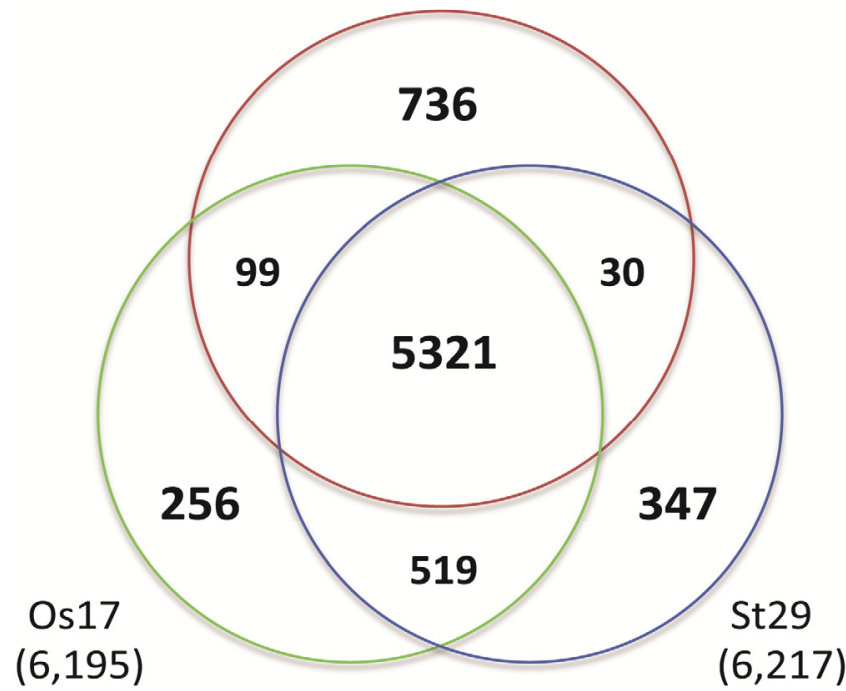

Fig. 1. Venn diagram comparing the coding sequence sets of Pseudomonas strains Os17 and St29 and Pseudomonas protegens Cab57. The number of orthologous coding sequences (CDS) shared by all strains is in the center. Numbers in the nonoverlapping portions of each circle represent the number of CDS unique to each strain. The total number of CDS within each genome is listed below the strain name. Each set of genes was compared with the other two sets using BLASTp, and sequence identity cut-off was set at $60 \%$ to identify common genes. Note that, owing to multiple hits, gene numbers do not add up to the strain totals.
The rhizoxin analog biosynthesis gene cluster in the Os17 genome, which was absent from the St29 genome.

We performed dot plot analysis to obtain an overview of chromosome-scale genomic syntenies among the strains of Os17, St29, and P. protegens Cab57 (Fig. 2). Compared with the Os17 genome, two large segments were absent from the St29 genome (Fig. 2A). One of these segments was a homolog of the complete $r z x$ gene cluster (approximately $79 \mathrm{~kb}$ ) (Supplementary Fig. S2), which has been reported to encode genes for the biosynthesis of analogs of the antimitotic macrolide rhizoxin in $P$. protegens Pf-5 (Loper et al. 2008). This cluster has been found to be absent from two other fully sequenced $P$. protegens strains, CHA0 and Cab57 (Takeuchi et al. 2014). In addition, another large segment was phage-related elements, as mentioned below. When comparing the genome of Os17 with that of Cab57, two large inversions were found (Fig. 2B). These two inversions were also found in the genome of St29 (data not shown).

At the upstream region of the $r z x$ gene cluster, the fit cluster encoding a functional insect toxin reported in $P$. protegens
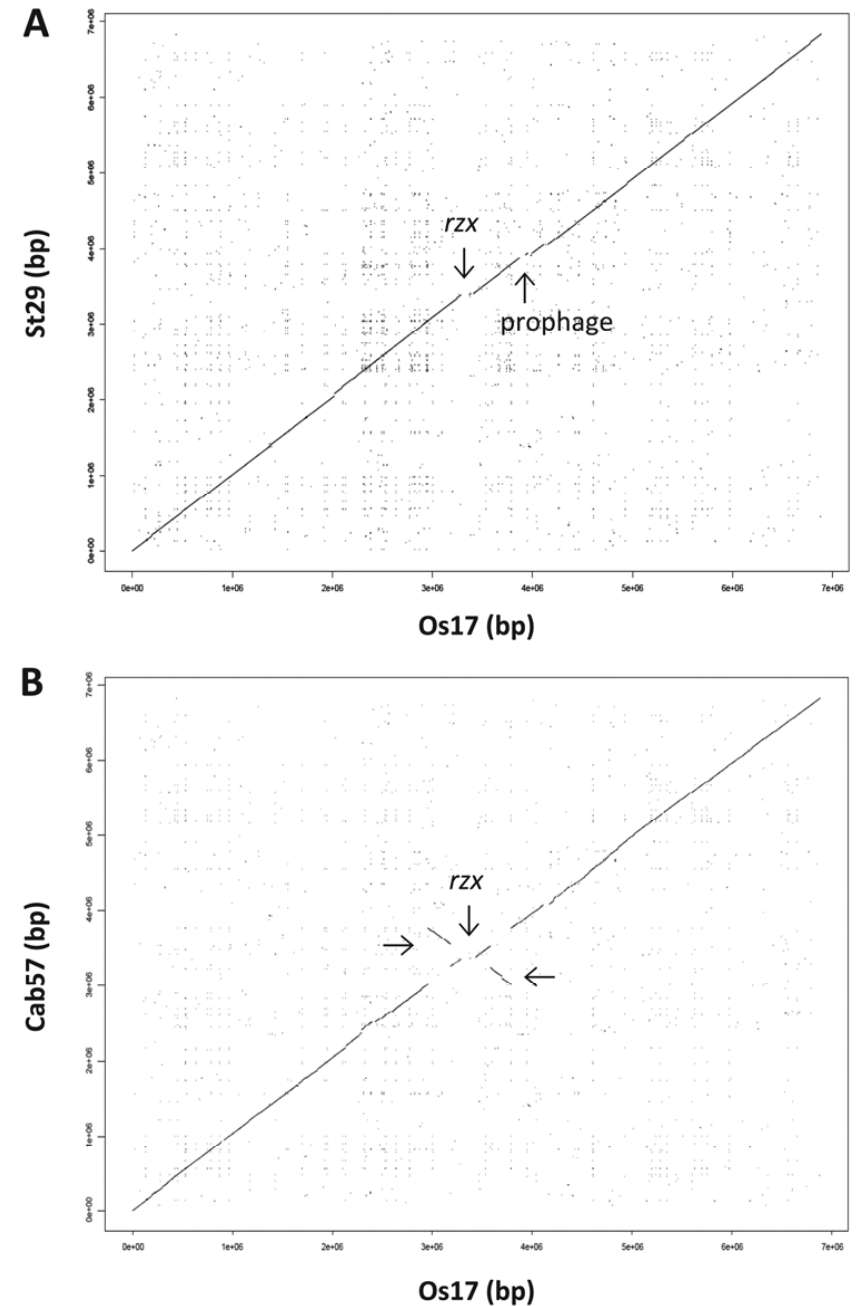

Fig. 2. Syntenic dot plot of Pseudomonas strain. Dot plot comparison of $\mathbf{A}$, the Os17 genome versus the St29 genome and B, the Os17 genome versus the $P$. protegens Cab57 genome. The line represents the regions of similarities between the two genomes, while discontinuities in this syntenic line represent regions of genomic variations at a given locus between the two strains. The position of the biosynthetic gene cluster for rhizoxin analogs in the Os17 genome is indicated by arrows ( $r z x$ in A and B). Positions of phage-related elements are also marked by an arrow (prophage in A). Genomic inversions observed between the genomes of Os17 and Cab57 are marked by horizontal arrows in B. 
CHA0 (Péchy-Tarr et al. 2008) was found to be conserved in the Os17 genome. This cluster is also conserved in the St29 genome.

\section{Regions unique to the Os17 genome.}

Apart from the rhizoxin analog biosynthesis gene cluster unique to the Os17 genome, another large segment found in dot plot analysis with the St29 genome was the region for phage-related elements (Fig. 2). This segment corresponds to the gene ID 3421-3565 of the Os17 genome and the gene ID 3520-3546 of the St29 genome, both of which consist of regions unique to each other. Gene ID 3421-3565 of the Os17 genome showed similarity to Cab57 prophages III and IV over the region and partly homologous to Cab57 prophage I, which have been previously reported in the Cab57 genome (Takeuchi et al. 2014). Gene ID 3520-3546 of the St29 genome contains five genes for transposase, suggesting that this region is relevant to transposons, and it also contains six genes involved in pilus assembly. This transposon-like region was absent from the Cab57 genome.

As other large regions unique to the Os17 genome, apart from the $r z x$ gene cluster, we listed regions including at least four continuous ORFs missing in the St29 and Cab57 genomes (Supplementary Table S5, clusters O1 to O9). Among these
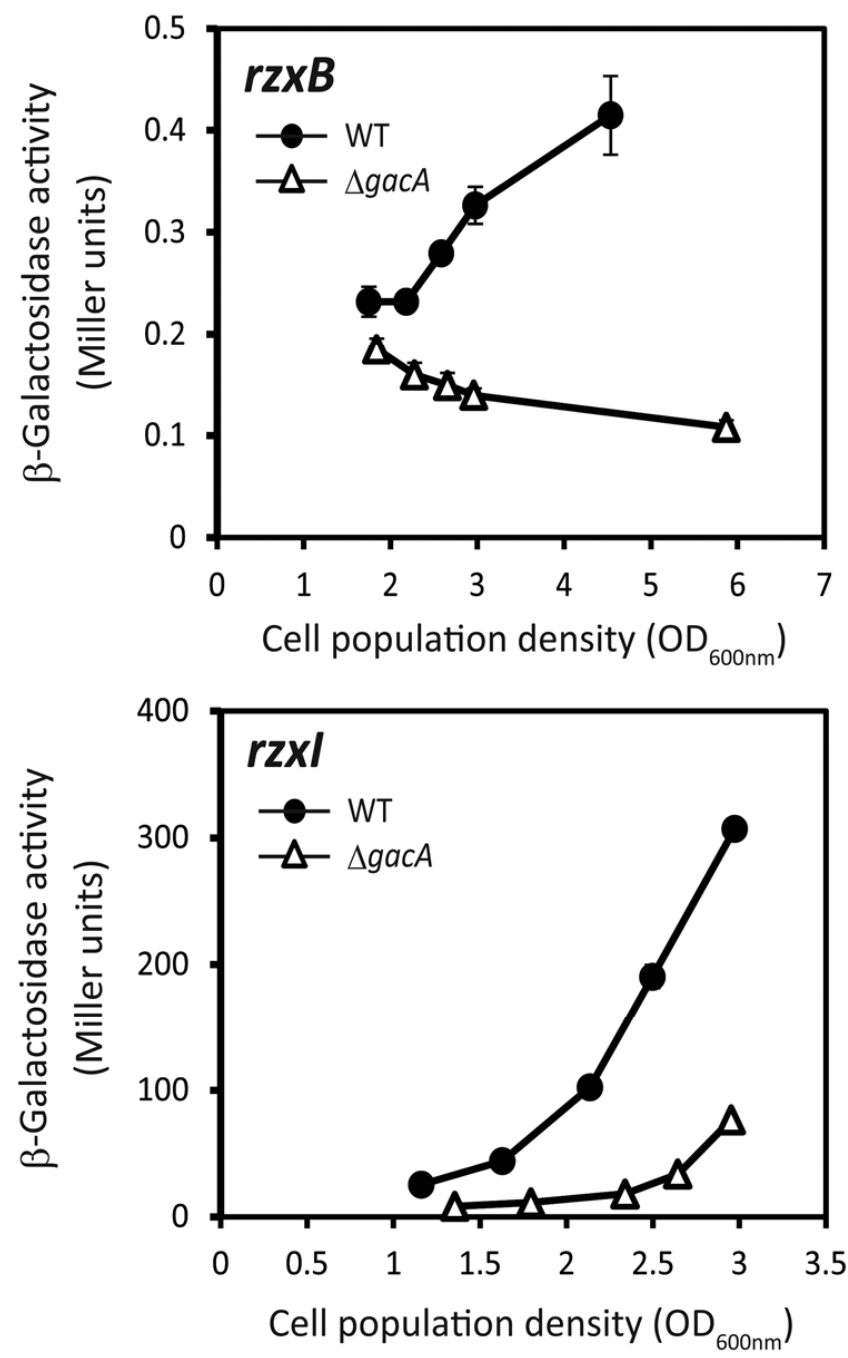

Fig. 3. Expression of an $r z x B^{\prime}-' l a c Z$ fusion on pME6014rzxB and an $r z x I^{\prime}$ 'lacZ fusion on pME6014rzxI in Os17 and the gacA mutant grown in nutrient yeast broth. Symbols indicate averages of triplicate cultures and bars indicate standard deviations. $\mathrm{OD}_{600 \mathrm{~nm}}=$ optical density at $600 \mathrm{~nm}$. clusters, clusters O5 (gene ID 3675-3692) and O6 (gene ID 3695-3712) caught our attention because these were identified as secondary metabolite clusters using the antiSMASH program. These two neighboring clusters are homologs of the biosynthetic cluster for the antibiotic mitomycin from Streptomyces lavendulae (Mao et al. 1999). Although the role of mitomycin in biocontrol has not been elucidated, such gene clusters may contribute to niche adaptation by this strain from an ecological viewpoint.

\section{Construction of the $r z x B$ mutant and its effect on rhizoxin analog production.}

Strain specificity of the complete $r z x$ gene cluster in the genome of Os17 among the three strains compared (Os17, St29, and Cab57) prompts us to predict that this region enables the strain to be superior to St29 as a biocontrol strain, and that it may compensate for the absence of plt and prn to exert its biocontrol activity at a level similar to that of strain Cab57. In a previous study, naturally isolated strains of Pseudomonas spp. that produce rhizoxin analog were shown to suppress phytopathogenic fungi and an oomycete in culture (Johansson and Wright 2003). Furthermore, the growth inhibition activities of
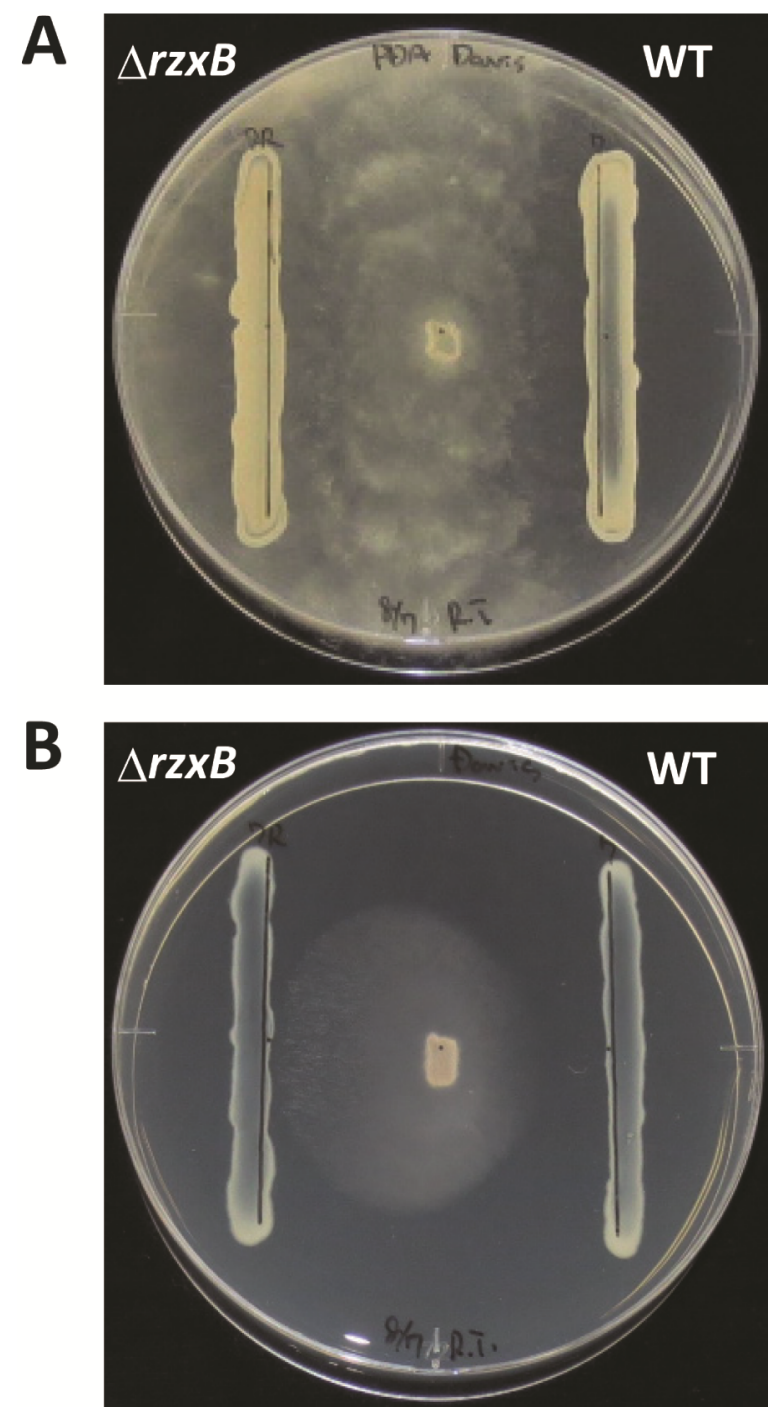

Fig. 4. Effects of the $r z x B$ mutation on antibiotic activity. Antibiotic activities of Pseudomonas sp. Os17 strains toward A, Pythium ultimum and B, Fusarium oxysporum were evaluated by the size of the growth inhibition zone. Antibiotic activities of Os17 wild type (WT) and the $r z x B$ mutant $(\Delta r z x B)$ were compared. 
rhizoxin and its analogous compounds toward fungus have been demonstrated (Iwasaki et al. 1984; Loper et al. 2008). Nevertheless, their role in biocontrol activity has not been assessed. To investigate the role of rhizoxin analogs in strain Os17, we constructed a rhizoxin-analog-negative mutant by knocking out the $r z x B$ gene, the first gene in the rhizoxin gene cluster. In $P$. protegens Pf-5, $r z x B$ had been annotated as polyketide synthase and reported to be essential for the production of rhizoxin analogs (Loper et al. 2008). The levels of production of the reported rhizoxin analogs (Rhizoxin, Rhizoxin D, WF-1360B, WF-1360C, WF-1360F, and 22Z-WF$1360 \mathrm{~F}$ ) were determined by liquid-chromatography mass spectrometry (LC-MS). In contrast to the wild type (Supplementary Fig. S3), accumulation of rhizoxin analogs in the $\operatorname{rzxB}$ mutant was below the detection limit (Supplementary Fig. S4). The wild type produced at least five rhizoxin analogs with [M $+\mathrm{H}]^{+}$peaks at $580,594,596,610$, and $626 \mathrm{~m} / z$ for $\mathrm{WF}-1360 \mathrm{C}$, Rhizoxin D, WF-1360B, 22Z-WF-1360F or WF-1360F, and Rhizoxin, respectively. At the $\mathrm{m} / \mathrm{z}$ of 594 and 626, multiple peaks were detected, suggesting the presence of isomers for each analog.

\section{A gac $A$ mutant exhibits decreased expression of $r z x B^{\prime}-' l a c Z$ and $r z x I^{\prime}-' l a c Z$ fusions.}

In $P$. protegens and other fluorescent pseudomonads, the GacS/GacA system positively controls the secondary metabolism. The production of rhizoxin analogs has also been reported to be under the control of GacA in $P$. protegens Pf-5, showing that, in the gacA mutant, the production was abolished and the levels of transcripts of two genes (PFL_2988 and PFL_2991) within the rhizoxin biosynthetic cluster were lower than those of the wild type (Hassan et al. 2010).

To determine whether the production of rhizoxin analogs in strain OS17 is under the control of the GacS/GacA system as well, we constructed a gacA mutant and determined the production levels of rhizoxin analogs by LC-MS. In the gacA mutant, the accumulation of rhizoxin analogs was below the detection limit (Supplementary Fig. S5).

In the Gac/Rsm signal transduction pathway of $P$. protegens CHA0, the RsmE (or RsmA) protein makes optimal contacts with an RNA sequence, $5^{\prime}-{ }^{A} /{ }_{U} C A N G G A N G U / A^{-}-3$, in which the central ribonucleotide forms a hexaloop (Shubert et al. 2007). In the rhizoxin biosynthetic cluster of the Os17 genome, the $r z x B$ gene (gene ID 2970, homolog of PFL_2989 in Pf-5) and the $r z x I$ gene (gene ID 2976, homolog of PFL_2995 in Pf5) have this consensus sequence in their upstream region. Therefore, we constructed translational $r z x B^{\prime}-{ }^{\prime} l a c Z$ fusion and $r z x I^{\prime}-{ }^{\prime} l a c Z$ fusion, and compared their expression in the wild type and the gacA mutant (Fig. 3; Supplementary Fig. S6). In the gacA mutant, a decreased level of expression was observed in both fusions at high cell densities, suggesting that GacAdependent regulation of these genes may account, at least in part, for the decreased level of rhizoxin analogs in the gacA mutant. Furthermore, the gacA mutant loses its antibiotic activity against $B$. subtilis, as reported in other biocontrol strains of pseudomonads (data not shown).

\section{An $r z x B$ mutant exhibited decreased antibiotic activity and biocontrol efficacy.}

We investigated whether the production of these compounds would affect the biocontrol efficacy in strain Os17 by utilizing the $r z x B$ mutant. In the $r z x B$ mutant, the growth inhibition activities against the phytopathogenic fungus Fusarium oxysporum and oomycete Pythium ultimum were attenuated (Fig. 4). These results indicate that the production of rhizoxin analogs may influence the biocontrol capacity of strain Os17. To investigate the influence of the $r z x B$ mutation in soil, we used a cucumber $-P$. ultimum pathosystem. In terms of biocontrol efficacy, the $r z x B$ mutant was less effective than the wild type (with 95\% confidence for survival test and shoot weight, and with $90 \%$ confidence for root weight) (Table 4). Both the wild type and the mutant reached similar levels of root colonization (Table 4).

In conclusion, comparative genome analysis of two newly isolated Pseudomonas strains was efficient to identify important biocontrol factors and to obtain an overview of traits of each strain. Among the regions specific to a more effective biocontrol strain, the complete rhizoxin analog biosynthesis gene cluster was characterized in detail for its role in biocontrol activity. Rhizoxin was first isolated from Rhizopus chinensis, a pathogenic fungus causing rice seedling blight with a symptom of abnormal swelling of roots, as its virulence factor (Iwasaki et al. 1984). Rhizoxin was then found to be produced by Burkholderia rhizoxinica, the bacterial endosymbiont of the fungus, but not by Rhizopus (Partida-Martinez and Hertweck 2005). The rhizoxin biosynthesis gene cluster ( $r h i$ gene cluster) was reported in B. rhizoxinica (Partida-Martinez and Hertweck 2007), and its whole-genome sequencing revealed that this cluster is encoded on the chromosome but not the megaplasmid carried by this strain (Lackner et al. 2011). The high conservation of this cluster between distant species (Pseudomonas protegens $\mathrm{Pf}-5$ or Pseudomonas sp. Os17 and B. rhizoxinica) suggests the evolutionary traces of horizontal gene transfer, although its mechanism is yet to be elucidated. Study of the distribution of this gene cluster in rhizosphere bacteria may provide intriguing insights into the interactions among benefi-

Table 4. Effects of $r z x B$ mutation on the suppression of Pythium damping-off and root rot of cucumber by Pseudomonas sp. strain Os17

\begin{tabular}{|c|c|c|c|c|c|}
\hline $\begin{array}{l}\text { Bacterial strain } \\
\text { added }^{w}\end{array}$ & $\begin{array}{l}\text { Pythium } \\
\text { added }^{\mathrm{w}}\end{array}$ & $\begin{array}{l}\text { Surviving plants } \\
\text { per flask }(\%)^{\mathrm{x}}\end{array}$ & $\begin{array}{l}\text { Shoot fresh weight } \\
\text { per flask }(g)^{\mathrm{x}}\end{array}$ & $\begin{array}{l}\text { Root fresh weight } \\
\text { per flask }(g)^{y}\end{array}$ & $\begin{array}{l}\text { Colonization by Pseudomonas } \\
\left(\log _{10} \text { CFU/g of root }\right)^{\mathrm{z}}\end{array}$ \\
\hline None & - & $100 \mathrm{a}$ & $0.71 \mathrm{a}$ & $0.30 \mathrm{a}$ & ND \\
\hline Os17 (wild type) & - & $100 \mathrm{a}$ & $0.65 \mathrm{a}$ & $0.29 \mathrm{a}$ & $7.06 \pm 0.13$ \\
\hline$\Delta r z x B$ & - & $100 \mathrm{a}$ & $0.70 \mathrm{a}$ & $0.30 \mathrm{a}$ & $6.88 \pm 0.17$ \\
\hline None & + & $2 \mathrm{c}$ & $0.18 \mathrm{~d}$ & $0.08 \mathrm{~d}$ & ND \\
\hline Os17 (wild type) & + & $85 \mathrm{a}$ & $0.43 \mathrm{~b}$ & $0.18 \mathrm{~b}$ & $8.25 \pm 0.21$ \\
\hline$\Delta r z x B$ & + & $58 \mathrm{~b}$ & $0.35 \mathrm{c}$ & $0.15 \mathrm{c}$ & $8.43 \pm 0.28$ \\
\hline
\end{tabular}

${ }^{\mathrm{w}}$ Pseudomonas strains were added at $10^{7} \mathrm{CFU} / \mathrm{g}$ of vermiculite contained within 100-ml flasks (30 g of soil per flask), after planting three 92-h-old, sterile-grown cucumber seedlings per flask. P. ultimum was added as a millet-seed inoculum at $2.5 \mathrm{~g} / \mathrm{kg}$ vermiculite before planting. Plants were harvested after 7 days.

${ }^{\mathrm{x}}$ Data represent the averages of 10 replicates (flasks containing three cucumber plants) per treatment without $P$. ultimum and 16 replicates per treatment with P. ultimum. Means within the same column followed by different letters (a to d) are significantly different $(P<0.05)$ according to Tukey's honestly significant difference (HSD) test.

${ }^{y}$ Data represent the averages of 10 replicates (flasks containing three cucumber plants) per treatment without $P$. ultimum and 16 replicates per treatment with P. ultimum. Means within the same column followed by different letters $(\mathrm{a}-\mathrm{d})$ are significantly different $(P<0.1)$ according to Tukey's HSD test.

${ }^{\mathrm{z}}$ The rhizosphere-stable plasmid pME6031 containing a tetracycline resistance determinant (Heeb et al. 2000) was introduced as a selective marker into the bacterial strains to determine their root colonization capacity in soil. $\mathrm{ND}=$ not detected. 
cial and phytopathogenic microbes and plants. Considering the metabolic load and the cost of harboring such a large cluster in the genome, it can be speculated that the $r z x$ cluster does not necessarily make the strain effective under conditions in which a simple lifestyle is preferable for survival. Indeed, there are many other biocontrol factors such as DAPG and HCN whose gene clusters are more common among biocontrol pseudomonad strains. The fact that Os17 was isolated from the rhizosphere of rice tempts us to speculate on whether the host plant species is relevant to the strain-specific genomic repertoires for the biosynthesis of secondary metabolites. Investigation of the interactions between rhizoxin analogs producing pseudomonads and host rice is a challenge for our future work.

Comparative genomics between closely related strains revealed phenotype-specific genes and enabled us to identify strain-specific biocontrol factors. In addition to the $r z x$ cluster, other Os17-specific gene clusters involved in secondary metabolites are also intriguing for our future study. Each repertoire of biocontrol factors may contribute to different potentials for niche adaptation in each strain.

\section{MATERIALS AND METHODS}

\section{Isolation of DAPG-producing pseudomonads from rhizosphere soil.}

For the isolation of fluorescent pseudomonads, plant roots were sampled on private lands in diverse locations (Hokkaido, Ibaraki, Kanagawa, Nagano, Aichi, and Nagasaki) in Japan after the land owners gave permission to conduct sampling on the sites. None of these plants is an endangered or protected species.

We isolated fluorescent pseudomonads based on a method described previously (Someya et al. 2012). DAPG-producing isolates were prescreened by PCR using the DAPG biosynthesis gene $p h l D$-specific primers $\mathrm{Phl} 2 \mathrm{a}$ and $\mathrm{Phl} 2 \mathrm{~b}$. phlD ${ }^{+}$isolates were incubated on dNBYG medium (Duffy and Défago 1999) and DAPG production was evaluated by TLC (Keel et al. 1992). DAPG production was also evaluated in strains Os17 and St 29 by HPLC (Schnider-Keel et al. 2000). Other antibiotic biosynthetic genes were also explored by PCR analysis using specific sets of primers: PRND1/PRND2 for PRN, PltBf/PltBr for PLT, and PM2/PM7-26R for HCN. Sequence analysis of $16 \mathrm{~S}$ rRNA genes was conducted as described previously (Someya et al. 2012).

\section{Bacterial strains and growth conditions.}

The bacterial strains and plasmids used are listed in Table 5. Escherichia coli and Pseudomonas strains were routinely grown in nutrient yeast broth (NYB) $(2.5 \%$ [wt/vol] nutrient broth and $0.5 \%$ [wt/vol] yeast extract) and Luria-Bertani medium with shaking, or on nutrient agar plates $(4 \%$ [wt/vol] blood agar base and $0.5 \%$ [wt/vol] yeast extract) amended with the following antibiotics, when required: ampicillin, $100 \mu \mathrm{g} / \mathrm{ml}$; kanamycin, $25 \mu \mathrm{g} / \mathrm{ml}$; or tetracycline, $50 \mu \mathrm{g} / \mathrm{ml}(100 \mu \mathrm{g} / \mathrm{ml}$ for selection of Pseudomonas sp.). The inoculation temperatures were $30^{\circ} \mathrm{C}$ for Pseudomonas sp. and $37^{\circ} \mathrm{C}$ for E. coli. Pseudomonas sp. was grown in Davis minimal broth without dextrose containing $20 \mathrm{mM}$ glycerol (Davis-gly), which offers higher expression of $r z x B$ in P. protegens Pf-5 (Loper et al. 2008) for the assays concerning rhizoxin analogs.

\section{DNA manipulation.}

Small-scale plasmid extraction was performed with a QIAprep spin miniprep kit (Qiagen); large-scale preparations were obtained with a Qiagen plasmid midi kit (Qiagen). Chromosomal DNA from $P$. protegens was prepared with a Qiagen Genomic DNA buffer set and Genomic-tip (Qiagen). DNA fragments were purified from agarose gels with a QIAquick gel extraction kit (Qiagen). Oligonucleotides used are lislted in Supplementary Table S6.

\section{Whole-genome sequencing and assembly.}

Whole-genome sequencing was performed using Roche Genome Sequencer FLX+ technology provided by Eurofins Genomics K.K. (Tokyo). A shotgun library was prepared and subsequently sequenced, generating 322,380 reads in 154.0 Mbp of sequencing data for Os17 and 322,577 reads in 191.5 Mbp of sequencing data for St29. An 8-kb-long paired-end library was also prepared and sequenced, generating 363,796 reads in 60.6 Mbp of sequencing data for Os17 and 301,760 reads in 45.4 Mbp of sequencing data for St29. Co-assembly of the results of both shotgun and paired-end sequencing was performed using Newbler 2.6, with full assembly into 43 (for Os17) and 38 (for St29) large contigs, defined as $>1 \mathrm{~kb}$. These

Table 5. Bacterial strains and plasmids used in this study

\begin{tabular}{|c|c|c|}
\hline Strain or plasmid & Description $^{z}$ & Source or reference \\
\hline \multicolumn{3}{|l|}{ Strains } \\
\hline \multicolumn{3}{|l|}{ Bacillus subtilis } \\
\hline M168 & Wild type & C. Keel \\
\hline \multicolumn{3}{|l|}{ Escherichia coli } \\
\hline DH5 $\alpha$, HB101 & Laboratory strains & Sambrook et al. 2001 \\
\hline \multicolumn{3}{|c|}{ Pseudomonas protegens } \\
\hline Cab57 & Wild type & Takeuchi et al. 2014 \\
\hline \multicolumn{3}{|l|}{ Pseudomonas sp. } \\
\hline Os17 & Wild type & This study \\
\hline Os17gacA & $\triangle g a c A$ & This study \\
\hline Os17rzxB & $\Delta r z x B$ & This study \\
\hline St29 & Wild type & This study \\
\hline \multicolumn{3}{|l|}{ Plasmids } \\
\hline pCR-Blunt II-TOPO & Cloning vector, pUC ori $\mathrm{Km}^{\mathrm{r}}$ & Invitrogen \\
\hline pME497 & Mobilizing plasmid, IncP-1, Tra, RepA(Ts); $\mathrm{Ap}^{\mathrm{r}}$ & Voisard et al. 1988 \\
\hline pME3087 & Suicide vector, ColE1 replicon, Mob; $\mathrm{Tc}^{\mathrm{r}}$ & Voisard et al. 1994 \\
\hline pME3087gacA & pME3087 containing a BamHI/HindIII $1.5-\mathrm{kb}$ gacA region containing a deletion of the $g a c A$ gene; $\mathrm{Tc}^{\mathrm{r}}$ & This study \\
\hline pME3087rzxB & pME3087 containing a BamHI/HindIII 1.6-kb $r z x B$ region containing a deletion of the $r z x B$ gene; Tc ${ }^{\mathrm{r}}$ & This study \\
\hline pME6014 & Cloning vector for construction of translational 'lacZ fusions; $\mathrm{Tc}^{\mathrm{r}}$ & Blumer et al. 1999 \\
\hline pME6014rzxB & Translational $r z x B^{\prime}-{ }^{\prime} l a c Z$ fusion under ptac; $\mathrm{Tc}^{\mathrm{r}}$ & This study \\
\hline pME6014rzxI & Translational $r z x I^{\prime}-{ }^{\prime} l a c Z$ fusion under ptac; $\mathrm{Tc}^{\mathrm{r}}$ & This study \\
\hline pME6031 & pACYC177-pVS1 shuttle vector; $\mathrm{Tc}^{\mathrm{r}}$ & Heeb et al. 2000 \\
\hline
\end{tabular}

${ }^{\mathrm{z}} \mathrm{Km}^{\mathrm{r}}, \mathrm{Ap}^{\mathrm{r}}$, and $\mathrm{Tc}^{\mathrm{r}}=$ resistant to kanamycin, ampicillin, and tetracycline, respectively. 
contigs could be manually integrated into only one scaffold for each organism using BLAST and the Staden software package. The sizes of the resulting scaffolds were $6.89 \mathrm{Mbp}$ for Os17 and $6.83 \mathrm{Mbp}$ for St29. The scaffolds did not contain gaps. The prediction of putative coding sequences and gene annotation was performed using the Microbial Genome Annotation Pipeline.

\section{Accession numbers.}

The complete genome sequences of Pseudomonas sp. Os17 and Pseudomonas sp. St29 have been deposited in the DDBJ/EMBL/GenBank database under accession numbers AP014627 and AP014628, respectively.

\section{Species identification and phylogenetic tree construction.}

To identify species, whole-genome comparisons of strain Os17 or St29 with those of the P. fluorescens group were performed using the JSpecies program (Richter and RossellóMóra 2009). This program is commonly used to compare two genomes and uses BLAST software (Altschul et al. 1990). A phylogenetic tree was constructed using REALPHY (Bertels et al. 2014) with whole genomes of sequenced Pseudomonas species, applying the Pf-5 genome as a reference.

\section{Comparative genome analysis.}

To compare the whole genomes of Pseudomonas sp. Os17, Pseudomonas sp. St29, and $P$. protegens Cab57, the alignment data between each pair of strains' genome sequences were prepared using the LASTZ program (release 1.02.00), and dot plots were then produced from the alignment data using $\mathrm{R}$ (version 3.0.1). Genomic regions that were unique to each strain were searched for using the Island Viewer program (Langille et al. 2010) and verified manually. Secondary metabolite production clusters were examined using the antiSMASH program (Blin et al. 2013).

\section{Plant disease suppression assays.}

Biocontrol activity of each strain was evaluated as described previously (Takeuchi et al. 2012), with slight modifications. Flasks containing $30 \mathrm{~g}$ of vermiculite were planted with three cucumber seedlings each and treated with Pythium ultimum MAFF425494. Pseudomonas strains were added to soil as a suspension ( $3 \mathrm{ml}$ per flask) of cells washed twice in sterile distilled water to give $1 \times 10^{7} \mathrm{CFU}$ per $\mathrm{g}$ of soil. Control flasks received the same amount of sterile water. Seedlings were covered with $5 \mathrm{~g}$ of untreated vermiculite and flasks were sealed with aerated silicon caps. The microcosms were incubated in a growth chamber at $60 \%$ relative humidity and $26^{\circ} \mathrm{C}$ with light for $16 \mathrm{~h}$, followed by an 8-h dark period. No watering was necessary. After 7 days of incubation, the biocontrol activity and root colonization of each strain were assessed. Data in Tables 1 and 4 represent the means from two individual repetitions of the same experiment, except for the result of root weight in Table 1, which represents the result of each experiment. Data of both experiments were first analyzed for a trial by treatment interaction by analysis of variance, which indicated that the data from the two independent trials could be pooled, except for the result of root weight in Table 1. Means were separated using Tukey's honestly significant difference test (at $P \leq 0.05$, except for the root weight in Table 4, for which $P \leq 0.1$ was used). Data for CFU counts were $\log _{10^{-}}$ transformed prior to statistical analysis. Statistical analysis was performed using $\mathrm{R}$ (version 3.0.1).

\section{Generation of $g a c A$ - and $r z x B$-negative mutant.}

A deletion of the chromosomal gacA gene and a not-inframe deletion in the chromosomal $r z x B$ gene of Pseudomonas sp. Os17 were created as follows. For gacA, fragments of 750 bp located upstream and 740 bp located downstream of the gacA gene were amplified by PCR with the primer pairs GacAUF/GacAUR and GacADF/GacADR, respectively. For $r z x B$, fragments of $790 \mathrm{bp}$ located at positions 6,790 to 7,580 of the $r z x B$ gene and $780 \mathrm{bp}$ located at positions 9,400 to 10,180 of the $r z x B$ gene were amplified by PCR with the primer pairs RzxBUF/RzxBUR and RzxBDF/RzxBDR, respectively. For these amplifications, high-fidelity DNA polymerase KOD Plus (Toyobo) and genomic DNA of Pseudomonas sp. Os17 as a template were used.

Each of the two corresponding fragments was annealed and amplified as a 1.5- or 1.6-kb fragment using the primer pair GacAUF/GacADR or RzxBUF/RzxBDR, respectively. These $1.5-$ and $1.6-\mathrm{kb}$ fragments were cloned into pCR-Blunt IITOPO (Invitrogen). The obtained inserts were confirmed by sequencing and digested with Bam HI and HindIII. After sequencing, these fragments were subcloned into pME3087 cleaved at the BamHI and HindIII sites to give pME3087gacA or pME3087rzxB. These plasmids were mobilized from $E$. coli DH5 $\alpha$ to Pseudomonas sp. Os17 by triparental mating with $E$. coli HB101/pME497. Excision of the vector via a second crossing-over was obtained after the enrichment of tetracycline-sensitive cells, generating the gacA or $r z x B$ mutant.

\section{Construction of $r z x B^{\prime}-' l a c Z$ and $r z x I^{\prime}$-'lacZ fusion.}

A 360- or 210-bp EcoRI-BamHI fragment from the upstream region of $r z x B$ or $r z x I$ was amplified using primer sets of RzxBproF/RzxBproR or RzxIproF/RzxIproR, and inserted into pME6014 to obtain pME6014rzxB or pME6014rzxI containing a translational $r z x B^{\prime}-{ }^{\prime} l a c Z$ or $r z x I^{\prime}-' l a c Z$ fusion, respectively.

\section{Detection of rhizoxin analogs.}

To detect the rhizoxin analogs, spent culture supernatant extracts of strain Os17 and the mutants were prepared. The strains were grown with shaking $(160 \mathrm{rpm})$ in 0.5 liters of Davis-gly medium at $25^{\circ} \mathrm{C}$. After $48 \mathrm{~h}$ of incubation, cells were collected (calculated as $\mathrm{OD}_{600} \times$ sampling volume of culture in milliliters of approximately 600), and the supernatant was extracted with ethyl acetate and evaporated to dryness. The crude extracts were dissolved in $600 \mu \mathrm{l}$ of $\mathrm{MeOH}$, and 10 $\mu \mathrm{l}$ was evaluated by LC-MS using a $2-\mathrm{mM}$ ammonium acetatebuffered $\mathrm{MeOH} / \mathrm{H}_{2} \mathrm{O}$ gradient, increasing the $\mathrm{MeOH}$ from 10 to $95 \%$ over $10 \mathrm{~min}$ and holding it at $100 \% \mathrm{MeOH}$ for $10 \mathrm{~min}$ (Cadenza CD-C 18 ; 150 by $2.0 \mathrm{~mm} ; 3-\mu \mathrm{m}$ column; $0.20 \mathrm{ml} / \mathrm{min}$ flow rate, with total ion current and photodiode array monitoring with a wavelength range of 190 to $800 \mathrm{~nm}$ ). LC-MS measurements were performed using a Q Exactive LC-MS Mass Spectrometer with an electrospray ion source (Thermo Fisher Scientific). Preparative HPLC was performed on a Shimadzu Nexera HPLC system. The positive ion mass spectra were obtained in full ion-scan mode (scanning range $\mathrm{m} / \mathrm{z}, 100$ to $\mathrm{m} / \mathrm{z}$ $1,500)$ at a resolution of 140,000 . LC-MS was performed by Toray Research Center Inc., Otsu, Japan.

\section{$\beta$-Galactosidase assays.}

$\beta$-Galactosidase activities were quantified by the Miller method (Miller 1972). Pseudomonas protegens strains were grown at $30^{\circ} \mathrm{C}$ in $50-\mathrm{ml}$ flasks containing $15 \mathrm{ml}$ of NYB supplemented with $0.05 \%$ Triton $\mathrm{X}-100$ with shaking at $180 \mathrm{rpm}$. Triton X-100 was required to prevent cell aggregation.

\section{Detection of antibiotic activity.}

The antibiotic activities of Pseudomonas strains were determined with Bacillus subtilis M168, Pythium ultimum MAFF425494, or F. oxysporum MAFF103054 as the reporter. Cul- 
tures of Pseudomonas strains were adjusted to $\mathrm{OD}_{600}=1.0$ for the assay with $B$. subtilis, and 5- $\mu$ l samples were spotted onto a plate with glycerol-casamino acid medium (Maurhofer et al. 1998) or NBglu. After overnight incubation at $28^{\circ} \mathrm{C}$, cells of Pseudomonas strains were killed by UV irradiation on a transilluminator for $5 \mathrm{~min}$. An overlay of $B$. subtilis revealed antibiotic production by growth inhibition zones. Cultures of Pseudomonas strains were adjusted to $\mathrm{OD}_{600}=1.5$ for the assay with P. ultimum or F. oxysporum, 20- $\mu$ l samples were streaked around the edge of the Davis-gly plate (for $F$. oxysporum) or an 1:1 mixture of Davis-gly and potato dextrose agar plate (for $P$. ultimum), and an inoculum of P. ultimum or $F$. oxysporum was transferred to the center of the plate. The plate was incubated at room temperature until $P$. ultimum or $F$. oxysporum reached the edge of the plate. As a quantitative measurement, DAPG was extracted with ethyl acetate from cell cultures (three replicates) grown in 50-ml flasks containing $10 \mathrm{ml}$ of $\mathrm{NBglu}$ at $28^{\circ} \mathrm{C}$ for $20 \mathrm{~h}$ with shaking at $180 \mathrm{rpm}$. The extract was dried, dissolved in $100 \mu \mathrm{l}$ of methanol, and analyzed by HPLC. DAPG production was quantified as described previously (Schnider-Keel et al. 2000).

\section{ACKNOWLEDGMENTS}

We thank D. Haas for providing the bacterial strains and plasmids, S. Miyashita for help with $\mathrm{R}$ in the plant experiments, F. Bertels for help with REALPHY, and Y. Nakamura for technical assistance. This work was supported, in part, by the Program for the Promotion of Basic Research Activities for Innovative Biosciences (PROBRAIN); the Science and Technology Research Promotion Program for Agriculture, Forestry, Fisheries and Food Industry; JSPS KAKENHI Grant 24780045; and the NIAS Technical Support System.

\section{LITERATURE CITED}

Altschul, S. F., Gish, W., Miller, W., Myers, E. W., and Lipman, D.J. 1990. Basic local alignment search tool. J. Mol. Biol. 215:403-410.

Bertels, F., Silander, O. K., Pachkov, M., Rainey, P. B., and Nimwegen, E. 2014. Automated reconstruction of whole-genome phylogenies from short sequence reads. Mol. Biol. Evol. 31:1077-1088.

Blin, K., Medema M. H, Kazempour, D., Fischbach, M.A., Breitling, R., Takano, E., and Weber, T. 2013. antiSMASH 2.0-a versatile platform for genome mining of secondary metabolite producers. Nucleic Acids Res. 41:W204-W212.

Blumer, C., Heeb, S., Pessi, G., and Haas, D. 1999. Global GacA-steered control of cyanide and exoprotease production in Pseudomonas fluorescens involves specific ribosome binding sites. Proc. Natl. Acad. Sci. U.S.A. 96:14073-14078.

Duffy, B. K., and Défago, G. 1999. Environmental factors modulating antibiotic and siderophore biosynthesis by Pseudomonas fluorescens biocontrol strains. Appl. Environ. Microbiol. 65:2429-2438.

Goodman, A. L., Merighi, M., Hyodo, M., Ventre, I., Filloux, A., and Lory, S. 2009. Direct interaction between sensor kinase proteins mediates acute and chronic disease phenotypes in a bacterial pathogen. Genes Dev. 23:249-259

Gross, H., and Loper, J. E. 2009. Genomics of secondary metabolite production by Pseudomonas spp. Nat. Prod. Rep. 26:1408-1466.

Gross, H., Stockwell, V. O., Henkels, M. D., Nowak-Thompson, B., Loper, J. E., and Gerwick, W. H. 2007. The genomisotopic approach: A systematic method to isolate products of orphan biosynthetic gene clusters. Chem. Biol. 14:53-63.

Haas, D., and Défago, G. 2005. Biological control of soil-borne pathogens by fluorescent pseudomonads. Nat. Rev. Microbiol. 3:307-319.

Haas, D., and Keel, C. 2003. Regulation of antibiotic production in rootcolonizing Pseudomonas spp. and relevance for biological control of plant disease. Annu. Rev. Phytopathol. 41:117-153.

Hassan, K. A., Johnson, A., Shaffer, B. T., Ren, Q., Kidarsa, T. A., Elbourne, L. D. H., Hartney, S., Duboy, R., Goebel, N. C., Zabriskie, T. M., Paulsen, I. T., and Loper, J. E. 2010. Inactivation of the GacA response regulator in Pseudomonas fluorescens Pf-5 has far-reaching transcriptomic consequences. Environ. Microbiol. 12:899-915.

Heeb, S., Itoh, Y., Nishijyo, T., Schnider, U., Keel, C., Wade, J., Walsh, U., O'Gara, F., and Haas, D. 2000. Small, stable shuttle vectors based on the minimal pVS1 replicon for use in gram-negative, plant-associated bacteria. Mol. Plant-Microbe Interact. 13:232-237.

Heeb, S., Blumer, C., and Haas, D. 2002. Regulatory RNA as mediator in GacA/RsmA-dependent global control of exoproduct formation in Pseudomonas fluorescens CHA0. J. Bacteriol. 184:1046-1056.

Humair, B., González, N., Mossialos, D., Reimmann, C., and Haas, D. 2009. Temperature-responsive sensing regulates biocontrol factor expression in Pseudomonas fluorescens CHA0. ISME J. 3:955-965.

Iwasaki, S., Kobayashi, H., Furukawa, J., Namikoshi, M., Okuda, S., Sato, Z., Matsuda, I., and Noda, T. 1984. Studies on macrocyclic lactone antibiotics. VII. Structure of a phytotoxin "rhizoxin" produced by Rhizopus chinensis. J. Antibiot. 37:354-362.

Johansson, P. M., and Wright, S. A. 2003. Low-temperature isolation of disease-suppressive bacteria and characterization of a distinctive group of pseudomonads. Appl. Environ. Microbiol. 69:6464-6474.

Kay, E., Dubuis, C., and Haas, D. 2005. Three small RNAs jointly ensure secondary metabolism and biocontrol in Pseudomonas fluorescens CHA0. Proc. Natl. Acad. Sci. U.S.A. 102:17136-17141.

Kay, E., Humair, B., Dénervaud, V., Riedel, K., Spahr, S., Eberl, L., Valverde, C., and Haas, D. 2006. Two GacA-dependent small RNAs modulate the quorum-sensing response in Pseudomonas aeruginosa. J. Bacteriol. 188:6026-6033.

Keel, C., Schnider, U., Maurhofer, M., Voisard, C., Laville, J., Burger, U., Wirthner, P., Haas, D., and Défago, G. 1992. Suppression of root diseases by Pseudomonas fluorescens CHA0: Importance of the bacterial secondary metabolite 2,4-diacetylphloroglucinol. Mol. Plant-Microbe Interact. 5:4-13.

Kidarsa, T. A., Goebel, N. C., Zabriskie, T. M., and Loper, J. E. 2011. Phloroglucinol mediates cross-talk between the pyoluteorin and 2,4diacetylphloroglucinol biosynthetic pathways in Pseudomonas fluorescens Pf-5. Mol. Microbiol. 81:395-414.

Kim, Y. C., Leveau, J., McSpadden Gardener, B. B., Pierson, E. A., Pierson, L. S., III, and Ryu, C. M. 2011. The multifactorial basis for plant health promotion by plant-associated bacteria. Appl. Environ. Microbiol. 77:1548-1555.

Lackner, G., Moebius, N., Partida-Martinez, L., and Hertweck, C. 2011. Complete genome sequence of Burkholderia rhizoxinica, an endosymbiont of Rhizopus microsporus. J. Bacteriol. 193:783-784.

Langille, M. G., Hsiao, W. W., and Brinkman, F. S. 2010. Detecting genomic islands using bioinformatics approaches. Nat. Rev. Microbiol 8:373-382.

Lapouge, K., Schubert, M., Allain, F. H.-T., and Haas, D. 2008. Gac/Rsm signal transduction pathway of $\gamma$-proteobacteria: From RNA recognition to regulation of social behaviour. Mol. Microbiol. 67:241-253.

Loper, J. E., Henkels, M. D., Shaffer, B. T., Valeriote, F. A., and Gross, H. 2008. Isolation and identification of rhizoxin analogs from Pseudomonas fluorescens Pf-5 by using a genomic mining strategy. Appl. Environ. Microbiol. 74:3085-3093.

Loper, J. E., Hassan, K. A., Mavrodi, D. V., Davis, E. W., II, Lim, C. K., Shaffer, B. T., Elbourne, L. D., Stockwell, V. O., Hartney, S. L., Breakwell, K., Henkels, M. D., Tetu, S. G., Rangel, L. I., Kidarsa, T. A., Wilson, N. L., van de Mortel, J. E., Song, C., Blumhagen, R., Radune, D., Hostetler, J. B., Brinkac, L. M., Durkin, A. S., Kluepfel, D. A., Wechter, W. P., Anderson, A. J., Kim, Y. C., Pierson, L. S., III., Pierson, E. A., Lindow, S. E., Kobayashi, D. Y., Raaijmakers, J. M., Weller, D. M., Thomashow, L. S., Allen, A. E., and Paulsen, I. T. 2012. Comparative genomics of plant-associated Pseudomonas spp.: Insights into diversity and inheritance of traits involved in multitrophic interactions. PLoS Genet. 8:e1002784. Published online.

Mao, Y., Varoglu, M., and Sherman, D. H. 1999. Molecular characterization and analysis of the biosynthetic gene cluster for the antitumor antibiotic mitomycin C from Streptomyces lavendulae NRRL 2564. Chem. Biol. 6:251-263.

Maurhofer, M., Reimmann, C., Schmidli-Sacherer, P., Heeb, S., Haas, D., and Défago, G. 1998. Salicylic acid biosynthetic genes expressed in Pseudomonas fluorescens strain P3 improve the induction of systemic resistance in tobacco against tobacco necrosis virus. Phytopathology 88:678-684.

Miller, J. H. 1972. Experiments in Molecular Genetics. Cold Spring Harbor Laboratory Press, Cold Spring Harbor, NY, U.S.A.

Partida-Martinez, L. P., and Hertweck, C. 2005. Pathogenic fungus harbours endosymbiotic bacteria for toxin production. Nature 437:884-888.

Partida-Martinez, L. P., and Hertweck, C. 2007. A gene cluster encoding rhizoxin biosynthesis in "Burkholderia rhizoxina", the bacterial endosymbiont of the fungus Rhizopus microspores. Chem. Biochem. 8:41-45.

Paulsen, I. T., Press, C. M., Ravel, J., Kobayashi, D. Y., Myers, G. S., Mavrodi, D. V., DeBoy, R. T., Seshadri, R., Ren, Q., Madupu, R., Dodson, R. J., Durkin, A. S., Brinkac, L. M., Daugherty, S. C., Sullivan, S. A., Rosovitz, M. J., Gwinn, M. L., Zhou, L., Schneider, D. J., Cartinhour, S. W., Nelson, W. C., Weidman, J., Watkins, K., Tran, K., Khouri, H., Pierson, E. A., Pierson, L. S., III,, Thomashow, L. S., and Loper, J. E. 
2005. Complete genome sequence of the plant commensal Pseudomonas fluorescens Pf-5. Nat. Biotechnol. 23:873-878.

Péchy-Tarr, M., Bruck, D. J., Maurhofer, M., Fischer, E., Vogne, C., Henkels, M. D., Donahue, K. M., Grunder, J., Loper, J. E., and Keel, C. 2008. Molecular analysis of a novel gene cluster encoding an insect toxin in plant-associated strains of Pseudomonas fluorescens. Environ. Microbiol. 10:2368-2386.

Reimmann, C., Valverde, C., Kay, E., and Haas, D. 2005. Posttranscriptional repression of GacS/GacA-controlled genes by the RNA-binding protein RsmE acting together with RsmA in the biocontrol strain Pseudomonas fluorescens CHA0. J. Bacteriol. 187:276-285.

Richter, M., and Rosselló-Móra, R. 2009. Shifting the genomic gold standard for the prokaryotic species definition. Proc. Natl. Acad. Sci. U.S.A. 106:19126-19131.

Sambrook, J., Russell, D. W., and Irwin, N. 2001. Molecular Cloning: A Laboratory Manual, 3rd ed. Cold Spring Harbor Laboratory Press, Cold Spring Harbor, NY, U.S.A..

Schnider-Keel, U., Seematter, A., Maurhofer, M., Blumer, C., Duffy, B., Gigot-Bonnefoy, C., Reimmann, C., Notz, R., Défago, G., Haas, D., and Keel, C. 2000. Autoinduction of 2,4-diacetylphloroglucinol biosynthesis in the biocontrol agent Pseudomonas fluorescens $\mathrm{CHA} 0$ and repression by the bacterial metabolites salicylate and pyoluteorin. J. Bacteriol. 182:1215-1225.

Schubert, M., Lapouge, K., Duss, O., Oberstrass, F. C., Jelesarov, I., Haas, D., and Allain, F. H. 2007. Molecular basis of messenger RNA recognition by the specific bacterial repressing clamp RsmA/CsrA. Nat. Struct. Mol. Biol. 14:807-813.

Someya, N., Morohoshi, T., Ikeda, T., Tsuchiya, K., and Ikeda, S. 2012. Genetic diversity and ecological evaluation of fluorescent pseudomonads isolated from the leaves and roots of potato plants. Microbes Environ. 27:122-126

Takeuchi, K., Kiefer, P., Reimmann, C., Keel, C., Dubuis, C., Rolli, J., Vorholt, J. A., and Haas, D. 2009. Small RNA-dependent expression of secondary metabolism is controlled by Krebs cycle function in Pseudomonas fluorescens. J. Biol. Chem. 284:34976-34985.
Takeuchi, K., Yamada, K., and Haas, D. 2012. ppGpp controlled by the Gac/Rsm regulatory pathway sustains biocontrol activity in Pseudomonas fluorescens CHA0. Mol. Plant-Microbe Interact. 25:1440-1449.

Takeuchi, K., Noda, N., and Someya, N. 2014. Complete genome sequence of the biocontrol strain Pseudomonas protegens Cab57 discovered in Japan reveals strain-specific diversity of this species. PLoS One 9:e93683. Published online.

Valverde, C., Heeb, S., Keel, C., and Haas, D. 2003. RsmY, a small regulatory RNA, is required in concert with RsmZ for GacA-dependent expression of biocontrol traits in Pseudomonas fluorescens CHA0. Mol Microbiol. 50:1361-1379.

Voisard, C., Rella, M., and Haas, D. 1988. Conjugative transfer of plasmid RP1 to soil isolates of Pseudomonas fluorescens is facilitated by certain large RP1 deletions. FEMS (Fed. Eur. Microbiol. Soc.) Microbiol. Lett. 55:9-13.

Voisard, C., Bull, C. T., Keel, C., Laville, J., Maurhofer, M., Schnider, U., Défago, G., and Haas, D. 1994. Biocontrol of root diseases by Pseudomonas fluorescens CHA0: Current concepts and experimental approaches. Pages 67-89 in: Molecular Ecology of Rhizosphere Microorganisms. F. O'Gara, D. N. Dowling, and B. Boesten, eds. VCH Weinheim, Germany.

Winsor, G. L., Lam, D. K., Fleming, L., Lo, R., Whiteside, M. D., Yu, N. Y., Hancock, R. E., and Brinkman, F. S., 2011. Pseudomonas Genome Database: Improved comparative analysis and population genomics capability for Pseudomonas genomes. Nucleic Acids Res. 39:D596-D600.

Youard, Z. A., Mislin, G. L., Majcherczyk, P. A., Schalk, I. J., and Reimmann, C. 2007. Pseudomonas fluorescens CHA0 produces enantiopyochelin, the optical antipode of the Pseudomonas aeruginosa siderophore pyochelin. J. Biol. Chem. 282:35546-35553.

\section{AUTHOR-RECOMMENDED INTERNET RESOURCES}

Pseudomonas Genome database: www.pseudomonas.com

Microbial Genome Annotation Pipeline database: www.migap.org/index.php/en/aboutpipeline 